\title{
Produções Científicas Brasileiras em Psicologia sobre Violência contra Mulher por Parceiro Íntimo
}

\author{
Beatriz Gross Curia ${ }^{1}$ \\ ${ }^{1}$ Pontifícia Universidade Católica do Rio Grande do \\ Sul, RS, Brasil. \\ Júlia Carvalho Zamora ${ }^{1}$ \\ ${ }^{1}$ Pontifícia Universidade Católica do Rio Grande do \\ Sul, RS, Brasil. \\ Isadora Silveira Ligório ${ }^{1}$ \\ ${ }^{1}$ Pontifícia Universidade Católica do Rio Grande do \\ Sul, RS, Brasil.
}

\author{
Victória Dias Gonçalves ${ }^{1}$ \\ ${ }^{1}$ Pontifícia Universidade Católica do Rio Grande do \\ Sul, RS, Brasil. \\ Aline Ruoso ${ }^{1}$ \\ ${ }^{1}$ Pontifícia Universidade Católica do Rio Grande do \\ Sul, RS, Brasil. \\ Luísa Habigzang ${ }^{1}$ \\ ${ }^{1}$ Pontifícia Universidade Católica do Rio \\ Grande do Sul, RS, Brasil.
}

Resumo: A presente revisão sistemática objetivou analisar a produção científica de estudos empíricos da Psicologia brasileira sobre o fenômeno da violência contra a mulher por parceiro íntimo (VPI) publicada em revistas nacionais. Para tanto, os artigos foram pesquisados nas bases de dados SciELO, PsycINFO, PePSIC e Scopus, utilizando os descritores: "violência contra a mulher" ou "violência por parceiro íntimo" ou "violência conjugal" ou "violência doméstica". As buscas também foram realizadas com descritores em inglês. Após aplicação de critérios de inclusão e exclusão, a amostra final foi composta por 29 artigos. Por meio da Análise Temática, os objetivos e principais resultados dos estudos foram agrupados de acordo com o tema principal. Os resultados indicaram uma distribuição proporcional de publicações entre os últimos cinco anos, com maior produção no Sul e no Sudeste do país. Houve um equilíbrio entre estudos quantitativos e qualitativos, sendo prevalentes estudos realizados com participantes, principalmente com mulheres, e estudos com entrevistas individuais e uso de instrumentos psicométricos. Conclui-se que há prevalência de estudos que retratam aspectos individuais em relação ao fenômeno, que há um menor número de pesquisas com caráter preventivo, bem como com avaliações de efetividade de intervenções propostas. Ademais, há escassez de estudos que incluam homens autores de violência, estratégia importante para uma mudança efetiva. A Psicologia enquanto ciência e profissão compõe a rede de enfrentamento ao fenômeno da VPI e não só atua em diferentes serviços de atendimento, como também na produção acadêmica e científica, fomentando novas pesquisas sobre a temática e políticas públicas de enfrentamento.

Palavras-chave: Violência por Parceiro Íntimo, Violência de Gênero, Revisão Sistemática, Produção Científica.

\section{Brazilian Scientific Productions in Psychology on Violence against Women by Intimate Partner}

\begin{abstract}
The present systematic review aimed to analyze the scientific production of empirical studies of Brazilian psychology on the phenomenon of violence against women by intimate partner (IPV) published in national journals. To do so, the articles were searched in the SciELO, PsycINFO, PePSIC and Scopus databases, using the descriptors: "violence against women" or "intimate partner violence" or "domestic violence" or "domestic violence". The searches were
\end{abstract}


also performed with English descriptors. After applying inclusion and exclusion criteria, the final sample consisted of 29 articles. Through the Thematic Analysis, the objectives and main results of the studies were grouped according to the main theme. The results indicated a proportional distribution of publications between the last five years, with higher production in the South and Southeast of the country. There was a balance between quantitative and qualitative studies, being prevalent studies performed with participants, mainly with women, and studies with individual interviews and use of psychometric instruments. It is concluded that there is a prevalence of studies that portray individual aspects in relation to the phenomenon, that there is little incidence of preventive research, as well as of evaluations of the effectiveness of proposed interventions. In addition, there is a shortage of studies that include men as authors of violence, an important strategy for an effective change. Psychology as a science and profession composes the network to confront the phenomenon of IPV and not only acts in different services of attendance, but also in the academic and scientific production, fomenting new researches on the thematic and public policies of confrontation.

Keywords: Intimate Partner Violence, Gender Violence, Systematic Review, Scientific Production.

\section{Producciones Científicas Brasileñas en Psicología sobre la Violencia contra la Mujer por Pareja Íntima}

Resumen: La presente revisión sistemática objetivó analizar la producción científica de estudios empíricos de la Psicología brasileña sobre el fenómeno de la violencia contra la mujer por pareja íntima (VPI) publicada en revistas nacionales. Los artículos fueron investigados en las bases de datos SciELO, PsycINFO, PePSIC y Scopus, utilizando los descriptores: "violencia contra la mujer" o "violencia por pareja íntima" o "violencia conyugal" o "violencia conyugal" o "violencia doméstica" o "violencia doméstica". Las búsquedas también se realizaron con descriptores en inglés. Después de la aplicación de criterios de inclusión y exclusión, la muestra final se compuso de 29 artículos. Por medio del Análisis Temático, los objetivos y principales resultados de los estudios se agruparon de acuerdo con el tema principal. Los resultados indicaron una distribución proporcional de publicaciones entre los últimos cinco años, con mayor producción en el Sur y en el Sudeste del país. Se observó un equilibrio entre estudios cuantitativos y cualitativos, siendo prevalentes estudios realizados con participantes, principalmente con mujeres, y estudios con entrevistas individuales y uso de instrumentos psicométricos. Se concluye que hay prevalencia de estudios que retratan aspectos individuales en relación al fenómeno, que hay poca incidencia de investigaciones con carácter preventivo, así como con evaluaciones de efectividad de intervenciones propuestas. Además, hay escasez de estudios que incluyan hombres autores de violencia, estrategia importante para un cambio efectivo. La Psicología como ciencia y profesión compone la red de enfrentamiento al fenómeno de la VPI y no sólo actúa en diferentes servicios de atención, sino también en la producción académica y científica, fomentando nuevas investigaciones sobre la temática y políticas públicas de enfrentamiento.

Palabras clave: Violencia por Pareja Íntima, Violencia de Género, Revisión Sistemática, Producción Científica.

\section{Introdução}

Historicamente, diferentes manifestações de violência contra a mulher foram constantemente legitimadas, principalmente as que ocorrem no espaço doméstico. O Estado não intervinha nestas circunstâncias, uma vez que as compreendia como conflitos familiares restritos a soluções domésticas (Angelim, \& Diniz, 2009). Por muito tempo, a violência praticada 
no âmbito privado foi negligenciada pelos órgãos públicos, sustentando uma organização social que ampara as relações de poder desiguais entre mulheres e homens (Saffioti, \& Almeida, 1995).

A partir dos anos 1980, a violência doméstica passa a ser uma importante pauta de reivindicações feministas no país, que convocaram pesquisadoras/ es de diferentes áreas a produzir estudos científicos sobre a temática (Ribeiro, 2010). Os movimentos feministas deram visibilidade às formas de violência e aos contextos nas quais estas eram praticadas, contribuindo para o entendimento do fenômeno da violência contra a mulher como um problema de ordem pública e exigindo um maior envolvimento do Estado. Por meio da pressão social emergente deste movimento, surge o reconhecimento da necessidade da criação de políticas de proteção para mulheres em situação de violência (Angelim, \& Diniz, 2009). Nesse sentido, a década de 1980 marca um dos primeiros avanços no enfrentamento da violência com a criação das Delegacias da Mulher (Silveira, Nardi, \& Spindler, 2014). Nas décadas seguintes, foram realizadas diversas conferências e convenções nacionais e internacionais sobre a temática. Esses eventos tiveram uma importância significativa para a elaboração de leis que buscavam promover os direitos da mulher, bem como a regulamentação de serviços de proteção e atendimento (Angelim, \& Diniz, 2009).

Em 1994, durante a Assembleia Geral da Organização dos Estados Americanos, foi apresentada a Convenção Interamericana para Prevenir, Punir e Erradicar a Violência Contra a Mulher na cidade de Belém do Pará. No ano seguinte, o projeto foi promulgado, tornando-se um documento de referência mundial no enfrentamento à violência contra a mulher. O Brasil aprovou essa legislação em novembro de 1995, no entanto, passou a cumpri-la somente em 2001, após ser condenado pela Comissão Interamericana de Direitos Humanos por tolerar a violência cometida contra Maria da Penha (Bandeira, \& Almeida, 2015). O país foi acusado de descumprir os tratados da Convenção Americana de Direitos Humanos e da Convenção de Belém do Pará em que era signatário. Estes tratados garantem que as mulheres em situação de violência tenham o direito a defesa, ao passo que o autor de violência deve ser investigado pela polícia e pelo sistema de justiça, o que no caso de Maria da Penha Fernandes não ocorreu (Bandeira, \& Almeida, 2015).
Em 2002, a violência contra a mulher passa a ser considerada pela Organização Mundial da Saúde (OMS) como um grave problema de saúde pública e uma das formas de violação dos direitos humanos. Na intenção de prevenir e coibir todas as formas de violência contra a mulher foi promulgada no Brasil em 2006 a Lei no 11.340 (2006), conhecida como Lei Maria da Penha, em homenagem ao caso real, que dispõe sobre as redes de assistência e de proteção a mulheres em situação de violência doméstica e familiar. A partir desta legislação, foram criados os Juizados de Violência Doméstica e Familiar contra a Mulher e implementados atendimentos especializados a elas por equipes multidisciplinares. Além disto, a Lei prevê ações de conscientização e ressocialização de autores de violência (Lei no $11.340,2006$ ), medidas que são importantes para atingir uma perspectiva mais efetiva de mudança no contexto de relações íntimas permeadas de violência (Saffioti, 2001).

Ainda, a Lei Maria da Penha define os tipos de violência perpetradas contra a mulher e as classifica em cinco categorias: física, psicológica, sexual, moral e patrimonial. A violência física abarca qualquer ato que fira a integridade física da mulher. A violência psicológica é compreendida por qualquer conduta que cause dano emocional e diminua a autoestima da mulher, como ameaças, insultos, manipulação, humilhação ou chantagem. A violência sexual ocorre quando a mulher é constrangida a presenciar ou participar de relação sexual indesejada, quando tem de alguma forma seus direitos sexuais e reprodutivos limitados, como impedimento do uso de métodos contraceptivos, e quando é forçada a comercializar seu corpo. A violência patrimonial implica em reter ou destruir documentos pessoais, bens, instrumentos de trabalho e recursos econômicos da mulher. A violência moral, por sua vez, é qualquer conduta que configure calúnia, difamação ou injúria, ferindo a imagem da mulher (Lei no 11.340, 2006).

A violência contra a mulher caracteriza-se como uma forma de violência de gênero, pois ela ocorre em razão da pessoa alvo da violência pertencer ao gênero feminino e tem como base a manutenção de papéis sociais impostos a mulheres e homens (Muhlen, \& Strey, 2013; Scott, 1995). Atualmente, o Brasil ocupa o $5^{\circ}$ lugar em uma lista de 83 países no índice de feminicídio (Waiselfisz, 2015), que é o homicídio que ocorre contra o gênero feminino motivado por violência doméstica e familiar 
ou menosprezo e discriminação pela condição de ser mulher (Lei no 13.104, 2015).

No que tange às diferentes expressões da violência contra a mulher, o principal autor da agressão identificado é seu parceiro ou ex-parceiro íntimo (Waiselfisz, 2015). Segundo dados do primeiro semestre de 2016 da Central de Atendimento à Mulher, mais de $67 \%$ dos casos apontaram homens como autores da violência em relações heterossexuais (Brasil, 2016), corroborando com a afirmativa de que, em relações íntimas, a prevalência de violência é de autoria do homem contra a mulher (Krug, Dahlberg, Mercy, Zwi, \& Lozano, 2002), o que evidencia a vivência de desigualdade de gênero no relacionamento afetivo (Schraiber et al., 2007).

A violência contra a mulher por parceiro íntimo (VPI) caracteriza-se por atitudes que, dentro de uma relação íntima, provocam danos físicos, sexuais ou mentais (Rosa, Ramos, Melo, \& Melo, 2013). Este fenômeno apresenta consequências em dimensões não só individuais, mas também familiares e coletivas, incluindo impactos sociais significativos (Paixão, Gomes, Diniz, Couto, Vianna, \& Santos, 2014; Krug et al., 2002). São consequências conhecidas: isolamento social, incapacidade para exercer atividades laborais e, por conseguinte, perda de salário, prejuízo na realização de atividades cotidianas, além da limitação no cuidado consigo e com os outros (Mendonça, \& Ludermir, 2017).

No âmbito pessoal, como repercussões da violência às mulheres, são identificadas alterações em seu estado físico, psíquico e social. Segundo o Relatório Mundial sobre Violência e Saúde (Krug et al., 2002), mulheres que sofreram violência apresentam maior risco para uma saúde precária no futuro. Alguns dos prejuízos associados estão relacionados com dificuldade em se proteger contra gravidez indesejada ou doenças (saúde reprodutiva); doenças psicossomáticas, lesões e, por vezes, óbito (saúde física); e maiores índices de depressão, ansiedade, fobias, suicídio e tentativas de suicídio (saúde psicológica). A literatura demonstra que a exposição à violência provoca às mulheres maiores chances de desenvolver transtornos psicológicos como estresse pós-traumático, de humor ou por uso de substância (Fonseca, Ribeiro, \& Leal, 2012).

Ademais, a VPI também gera impacto nas/os filhas/os que a presenciam, pois estes estão mais propensos a apresentar problemas emocionais e com- portamentais, incluindo ansiedade, depressão, baixo rendimento escolar, baixa autoestima, desobediência, pesadelos e problemas de saúde física (OMS, 2002). Este dado é ainda mais expressivo quando se identifica o ambiente doméstico como principal local de ocorrência da violência (Waiselfisz, 2015).

O fenômeno da violência contra a mulher não se restringe às fronteiras de classe, escolaridade, religião, cultura ou grupo étnico (Krug et al.,, 2002; Saffioti, 1997), entretanto, deve ser reconhecido o atravessamento dessas características nas vivências de violência e de acesso à justiça (Silveira, \& Nardi, 2014). Um estudo analisou boletins de ocorrência (BOs) e processos judiciais de mulheres que sofreram violência na cidade de Porto Alegre. Foi registrado um número maior de BOs por mulheres negras, mas, por outro lado, a continuidade dos processos judiciais de mulheres negras cai pela metade quando comparado aos BOs, indicando que não há paridade entre mulheres negras e brancas no acesso à justiça em níveis mais avançados (Silveira, \& Nardi, 2014). Ademais, o Mapa da Violência de 2015 indica um aumento da violência e feminicídio contra mulheres negras (Waiselfisz, 2015), dados que evidenciam a importância de pesquisas sobre os marcadores de raça e etnia e sua intersecção com o marcador de gênero, para que sejam possíveis práticas jurídicas e psicológicas que busquem compreender as desigualdades reais vivenciadas por diferentes grupos étnico-raciais que reverberam no enfrentamento à violência (Silveira, \& Nardi, 2014).

Em razão dos impactos deste fenômeno, mulheres que sofreram violência demandam atendimento multiprofissional e qualificado, sendo a Psicologia uma área importante na rede de serviços de atenção (Conselho Federal de Psicologia - CFP, 2013). Conforme o documento de referências técnicas para atuação de psicólogas/os em programas de atenção à mulher em situação de violência (CFP, 2013), caberá a estas/es profissionais considerarem a violência contra a mulher como uma violação de direitos humanos e um produto da desigualdade de gênero legitimada pela sociedade. Diante dessas situações, deverão compreender que o enfrentamento à violência implica em adotar o posicionamento de que, em nenhuma circunstância, existe justificativa para a violência.

Além disso, psicólogas/os deverão ter, entre os princípios norteadores de suas práticas, o trabalho em equipe multidisciplinar, que se faz necessário no enfrentamento da violência, uma vez que ela exige a 
articulação de diferentes saberes, práticas e políticas. Para tanto, é importante que a/o profissional conheça a rede de atendimento à mulher, considerando os aspectos positivos e as fragilidades de cada serviço (CFP, 2013). Entre as principais práticas da Psicologia nos serviços de atendimento a mulheres em situação de violência estão o acolhimento, o planejamento dos atendimentos, o encaminhamento, o acompanhamento, o estudo de caso e a produção de documentos. É importante que em todas as intervenções, as/os profissionais estimulem a autonomia e fortaleçam o protagonismo das mulheres (CFP, 2013).

Além das práticas profissionais, a Psicologia tem importante contribuição no enfrentamento à violência por meio da produção acadêmica e científica. $\mathrm{O}$ ato de pesquisar deve também compreender uma dimensão ética e política, uma vez que provoca efeitos nos indivíduos e pode reafirmar ou desconstruir relações de desigualdade. Dessa forma, a Psicologia, enquanto ciência e profissão, pode desempenhar um importante papel na formulação de políticas públicas, apresentando-se como um dispositivo para a promoção de saúde e de direitos para as mulheres (Bicalho, Magalhães, Cassal, \& Geraldini, 2012). A perspectiva atual e futura da Psicologia está baseada na convergência da produção científica e de práticas profissionais, ou seja, em intervenções psicológicas sustentadas por evidências empíricas de efetividade (Leonardi, \& Meyer, 2015).

Este estudo é uma revisão sistemática da literatura que teve como objetivo analisar a produção científica de estudos empíricos da Psicologia brasileira sobre o fenômeno da violência contra a mulher perpetrada por parceiro íntimo publicada em revistas nacionais. Os objetivos específicos desta revisão foram: (1) mapear as regiões do Brasil nas quais os estudos foram produzidos; (2) analisar seus objetivos; (3) verificar métodos utilizados; (4) identificar as/os participantes das pesquisas; e (5) analisar os principais resultados.

\section{Método}

Essa revisão sistemática de literatura foi realizada conforme as etapas indicadas por Costa e Zoltowski (2014): (1) delimitação da questão a ser pesquisada; (2) seleção das bases de dados; (3) eleição das palavras-chave para busca; (4) procura e armazenamento de resultados; (5) seleção de artigos pelo resumo, de acordo com critérios de inclu- são e exclusão; (6) extração dos dados dos artigos selecionados; (7) avaliação dos artigos e (8) síntese e interpretação dos dados. Para tanto, foi feita uma busca por artigos científicos, realizada por duas juízas independentes, nas bases de dados Scientific Electronic Library Online (SciELO), PsycINFO, Periódicos Eletrônicos em Psicologia (PePSIC) e Scopus, no período de julho a agosto de 2017. Foram utilizados os seguintes descritores: "violência contra a mulher" OR "violência por parceiro íntimo" OR "violência conjugal" OR "violência doméstica". As buscas também foram realizadas nas mesmas bases com os descritores em inglês: "violence against woman" OR "marital violence" OR "domestic violence" OR "intimate partner violence".

A busca inicial resultou em 17.449 artigos, sendo nas bases SciELO ( $\mathrm{n}=844)$; PsycINFO ( $\mathrm{n}=398)$; PePSIC $(n=154)$ e Scopus $(n=16.053)$. Na sequência, os títulos e resumos dos artigos foram analisados a partir dos seguintes critérios de inclusão: (1) estudos empíricos, (2) publicados entre 2013 e 2017, (3) produzidos no Brasil e (4) publicados em revistas científicas nacionais. Com a aplicação dos critérios de inclusão, o número de artigos foi reduzido a 484. A fase seguinte foi excluir artigos repetidos, publicações que não fossem artigos científicos, que não versassem sobre violência contra a mulher praticada por parceiro íntimo e que não fossem da área da Psicologia. Ao final de todo o processo, a amostra foi composta por 29 artigos (Ver Figura).

Após a etapa de seleção, cada artigo foi lido na íntegra e analisado por duas juízas independentes. Os conteúdos dos 29 artigos foram analisados a partir das seguintes categorias: (1) ano de publicação e região do país onde foi realizado o estudo, (2) método (delineamento, participantes e instrumentos), (3) objetivos e principais resultados obtidos (Ver Tabela). Os resultados encontrados na categoria três foram analisados por meio da Análise Temática a partir da proposta de Braun e Clarke (2006), verificando o tema principal e agrupando os estudos com base em tais temas.

\section{Resultados}

Nos últimos cinco anos foram encontrados sete artigos empíricos em 2013 (4, 9, 11, 19, 21, 24 e 29), cinco em 2014 (16, 18, 25, 27 e 28), sete em 2015 (1, 2, $5,6,10,12$ e 22$)$, sete em $2016(3,7,15,17,20,23$ e 26) e, até o momento da busca, três em 2017 (8, 13 e 14). 


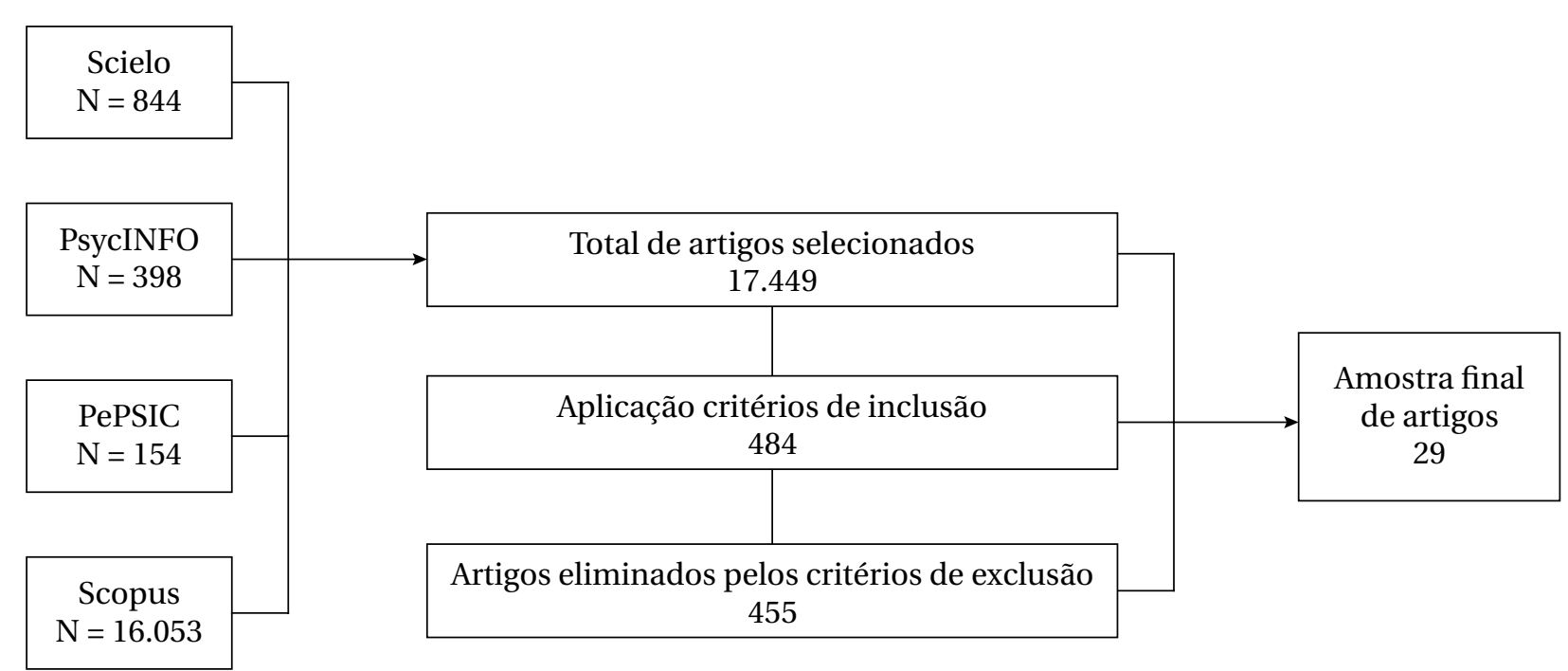

Figura 1.

Fluxograma das etapas de seleção dos artigos para revisão sistemática.

Fonte: Desenvolvida pelas autoras.

Já em relação às regiões brasileiras em que foram produzidos, verificou-se a seguinte distribuição: Norte (dois: 17 e 18), Nordeste (quatro: 1, 2, 11 e 27), Centro-Oeste (dois: 8 e 19), Sudeste (oito: 4, 9, 15, 21, 22, 23, 25 e 28), Sul (12: 3, 5, 6, 10, 12, 13, 14, 15, 20, 24, 27 e 29) e um sem região especificada do país (7).

Dos 29 estudos encontrados, 23 foram realizados com indivíduos e os demais por meio de análise documental. O número de pessoas que participaram dos estudos variou entre quatro e 372 . Nove estudos $(1,2,8$, 10, 11, 24, 25, 27 e 29) tiveram a participação de mulheres que vivenciaram violência, sendo que um destes incluiu suas/seus filhas/os adolescentes. Outros estudos foram realizados com profissionais da rede $(4,9,18$ e 28) e com homens e mulheres (5, 7, 16 e 19).

No que diz respeito a abordagem, houve um equilíbrio entre estudos qualitativos, que totalizaram $13(1,3,8,10,11,16,17,18,19,24,25,28$ e 29$)$ e quantitativos, que totalizaram $11(2,4,5,6,7,12,13,14$, 15,20 e 21). Cinco estudos optaram pela abordagem quantitativa-qualitativa $(9,22,23,26$ e 27).

O método empregado nos estudos também apresentou variabilidade. Utilizaram-se entrevistas em dez estudos (1, 10, 11, 18, 23, 24, 25, 27, 28 e 29) e houve aplicação de instrumentos psicométricos em sete $(2,5,6,12,13,20$ e 23$)$, sendo que cinco fizeram uso da Escala Tática de Conflitos (CTS2). Oito apresentavam intervenções $(4,8,9,16,17,19,23$ e 24), seis delas realizadas na modalidade grupal $(8,9,16,17,20$ e 24). Oito estudos fizeram uso da pesquisa documental $(3,9,14,15,21,22,26$ e 27$)$.

$\mathrm{Na}$ análise dos objetivos e resultados principais dos estudos, emergiram sete categorias: (1) crenças/ percepções sobre o fenômeno da violência, (2) caracterização da violência, (3) perfil da mulher vítima, (4) fatores de risco ou proteção para ocorrência de violência, (5) consequências da violência, (6) avaliação da rede de atendimento e (7) avaliação de intervenções. Dez estudos enquadraram-se em duas categorias $(2,6,8,14,15,21,24,26,27$ e 29) e os demais tiveram como foco somente uma. Em relação à primeira categoria, oito estudos se propuseram a verificar crenças/percepções sobre a violência contra a mulher ( 1 , $3,11,16,18,19,24$ e 29). Quatro foram realizados com mulheres que sofreram violência (1, 11, 24 e 29), em um deles com a participação de filhas/os (24). Ainda, dois foram realizados com mulheres e homens (16 e 19) e dois com profissionais da rede (3 e 18).

Sete estudos objetivaram caracterizar o fenômeno da violência contra a mulher $(2,6,14,15,21$, 26 e 29) que investigaram, principalmente, o tipo de violência prevalente (2, 6, 26 e 29). Três analisaram o perfil da mulher em situação de violência (2, 6 e 27). Nove investigaram os fatores de risco ou proteção associados à violência $(5,7,8,10,12,13,14,15,21 \mathrm{e}$ 24). Seis destes analisaram fatores individuais $(7,8$, $12,14,15$ e 21) e três investigara fatores familiares ou sociais (5, 13 e 24$)$. 
Tabela

Resultados das Categorias de Análise dos Estudos.

\begin{tabular}{lc}
\hline Autores/Ano/Região & Objetivo principal \\
\hline & $\begin{array}{c}\text { Compreender } \\
\text { percepções sobre } \\
\text { tentativa de } \\
(2015)\end{array}$ \\
& $\begin{array}{c}\text { homicídio e suicídio } \\
\text { do parceiro }\end{array}$
\end{tabular}

2. Barros, Silva, Falbo Neto, Lucena, Ponzo \& Pimentel (2015)

3. Bruhn, \& Lara (2016)

4. Brum, Lourenço, Gebara, \& Ronzani (2013)

5. Colossi, Marasca, \& Falcke (2015)

6. Colossi, Razera, Haack, \& Falcke (2015)

7. Costa et al. (2016)

8. Guimarães, Diniz, \& Angelim (2017)
Estimar prevalência e fatores associados à VPI

Analisar discursos da rede socioinstitucional sobre violência

Avaliar mudanças de crenças e atitudes em relação à violência doméstica

Identificar associações entre violência conjugal e experiências na família de origem

\section{Verificar}

prevalência de VPI

e correlacionar

com variáveis

sociodemográficas

Replicar estudo americano sobre naturalização da violência associada ao ciúme

Avaliar Teoria do Duplo Vínculo na violência e verificar efeitos de intervenção
Método

Qualitativo;

entrevistas individuais

semiestruturadas; três

mulheres que sofreram violência

Quantitativo; questionário sociodemográfico;

instrumentos psicométricos

(WVS e SRQ-20); 245

mulheres que sofreram violência

Qualitativo; pesquisa documental; um prontuário de usuária do serviço de acolhimento

Quantitativo; capacitação sobre uso de substâncias psicoativas e violência doméstica; questionário sociodemográfico e sobre práticas de prevenção à violência; 65 profissionais de saúde

Quantitativo; questionário sociodemográfico; instrumentos psicométricos (FBQ e CTS2); 300 mulheres e homens

Quantitativo; ficha sociodemográfica e instrumento psicométrico (CTS2); 186 casais heterossexuais

Quantitativo; análise de áudios com quatro situações diferentes; 264 estudantes universitárias/os

Qualitativo; leitura de livro, questionário e encontro grupal; 20 mulheres que sofreram violência
Principais Resultados

Relações conjugais permeadas por ciúme. A valorização da família nuclear e a preocupação excessiva com o companheiro influenciam na manutenção da relação

Maior prevalência em mulheres jovens, pretas ou pardas, sem companheiros, sem filhos e sem trabalho. Violência emocional mais frequente, seguida da física e da sexual

Discursos reforçam relações de poder baseadas na dualidade vítima-agressor, enfraquecendo a autonomia da mulher e percebendo a agressividade como traços de personalidade dos homens

Houve alterações em relação aos papéis de profissionais na identificação, no entendimento e manejo de violência doméstica

Correlações entre violência na família de origem e violência conjugal. Para mulheres, a negligência física, o abuso sexual e o abuso de substâncias paterno foram preditores da agressão, enquanto, para homens foi abuso físico paterno

Maior prevalência de violência psicológica, em casais jovens e economicamente desfavorecidos e com maior número de filhos. Maior coerção sexual por homens; maior violência psicológica grave por mulheres

Agressão em situação de ciúme é aceita culturalmente. Respostas foram semelhantes entre mulheres e homens

Dificuldade em avaliar riscos e romper relação violenta pela ambiguidade de sentimentos sobre

o parceiro. Intervenção auxiliou na quebra do duplo-vínculo e conscientização da violência

Continua 
Continuação

9. Kind, Orsini, Nepomuceno, Gonçalves, Souza, \& Ferreira (2013)

10. Krenkel, Moré \& Motta (2015)

11. Lacerda, \& Costa (2013)

12. Madalena, Falcke, \& Carvalho (2015)

13. Marasca, Razera, Pereira, \& Falcke (2017)

14. Martins-Borges, Girardi, \& Lodetti (2017)

15. Martins-Borges, Lodetti, Tridapalli, \& Machado (2016)

16. Oliveira, \& Araújo (2014)

17. Pimentel (2016)

18. Porto, \& Buchrer-Maluschke (2014)

$$
\begin{gathered}
\text { Identificar } \\
\text { indicadores } \\
\text { de violência e } \\
\text { dificuldades de } \\
\text { profissionais na } \\
\text { notificação }
\end{gathered}
$$

\section{Compreender o} papel da rede de apoio para mulheres

Identificar percepções sobre ciúmes e violência

Investigar relações entre funcionamento patológico da personalidade e níveis de violência

Avaliar a violência física nos relacionamentos e relação com família de origem

Caracterizar casos de homicídios conjugais

\section{Caracterizar casos de homicídios conjugais}

Identificar
crenças sobre
enfrentamento à
violência

Avaliar intervenção clínica sobre violência

Identificar crenças de psicólogas sobre mulheres em situação de violência
Quantitativo-qualitativo; pesquisa documental, questionário; grupos

focais; dados de saúde; 302 profissionais de saúde

Qualitativo; entrevista semiestruturada; 12 mulheres que sofreram violência

Estudo de caso qualitativo; entrevista semiestruturada; 10 mulheres que sofreram violência

Quantitativo; instrumentos psicométricos (IDCP

e CTS2);139 casais heterossexuais

Quantitativo; questionário sociodemográfico (FBQ e CTS2); 186 homens

Quantitativo; pesquisa documental em jornais sobre casos de homicídios conjugais; 34 casos

Quantitativo; pesquisa documental em jornais sobre casos de homicídios conjugais; 144 casos

Qualitativo; oficina dramática; 76 mulheres e homens

Qualitativo; grupo existencial fenomenológico; seis homens autores de violência

Qualitativo; questionário sociodemográfico e online, Entrevista semiestruturada, Escala sobre atendimento psicológico e de formação em Psicologia; 12 psicólogas
Crescimento anual gradativo de notificações de violência. A notificação é frequentemente entendida como denúncia por profissionais

A rede de apoio é significativa no enfrentamento da violência, tendo múltiplas funções (companhia, suporte emocional, aconselhamento)

Ciúme entendido como psicopatologia. O comportamento ciumento é reforçado socialmente e está atrelado à violência

A escolha conjugal pode reforçar funcionamento patológico da personalidade. Tendência de aproximação entre indivíduos com características semelhantes de personalidade. Associações são fracas

Correlação significativa entre violência física (cometida e sofrida) e violência na família de origem. Homens reportaram serem mais vítimas do que perpetradores

Aumento dos casos nos últimos anos. Maioria cometida por homens com armas de fogo, já separados, motivados por ciúme e separação e com situações prévias de violência

Maior incidência na região catarinense. Maioria cometida por homens com armas de fogo, já separados, motivados por ciúme e separação e com situações prévias de violência

Principais estratégias de enfrentamento: revidar com mais violência, fugir do lar, resolver a situação no espaço privado

(descrença no judiciário)

Reflexões críticas sobre diferenças na construção da subjetividade de homens e mulheres

Aspectos sociais, ciúme e autossacrifício influenciam na permanência de mulheres em situações de violência para psicólogas

Continua 
Continuação

19. Ramos (2013)

20. Razera, Mosmann, \& Falcke (2016)

21. Romagnoli, Abreu, \& Silveira (2013)

22. Romagnoli (2015)

23. Santini, \& Williams (2016)

24. Santos, Marin \& Castoldi (2013)

25. Silva, \& Tilio (2014)

26. Silva, Alípio, \& Moreira (2016)

$$
\begin{aligned}
& \text { Analisar papéis } \\
& \text { e comunicação } \\
& \text { conjugal }
\end{aligned}
$$

Investigar associação entre qualidade conjugal e violência

Tipificar atos violentos contra a mulher

Analisar a implementação da Lei Maria da Penha na rede

Avaliar intervenção de habilidades parentais

Explorar a percepção de mulheres e filhas/os sobre violência

Analisar alterações autobiográficas após situação de violência

Analisar registros de casos e atividades de juizado especializado
Qualitativo; intervenção socioterapêutica grupal para homens e mulheres; 30 mulheres e homens

Quantitativo; questionário sociodemográfico; instrumentos psicométricos (GRIMS e CTS2); 186 casais heterossexuais

Quantitativo; pesquisa documental; 1.315 boletins de ocorrência

Quantitativo-qualitativo; pesquisa documental e análise institucional; 1.315 boletins de ocorrência

Quantitativo-qualitativo; encontros individuais; instrumentos psicométricos

(CAP, BDI e Registro de

Bem-Estar e de Senso de Competência Parental); nove mulheres/mães que sofreram violência

Estudo de casos múltiplos qualitativo; encontro com mães e com filhas/os; entrevistas individuais; três mulheres/mães que sofreram violência e três filhas/os

Estudo de caso qualitativo; participação no acolhimento em centro de referência; entrevista semiestruturada; três mulheres que sofreram violência

Qualitativo-quantitativo; análise documental; relato de experiência com diário de campo; 227 cadastros psicossociais
Ambos se sentem agressores e vítimas e a agressão é justificada por ambos. Os encontros proporcionaram novas formas interacionais

Quanto mais violência, principalmente a psicológica, menor qualidade conjugal percebida. $80 \%$ dos casais pratica e a maioria segue satisfeita com a relação

Maior ocorrência em bairros de periferia. Maioria das mulheres e homens casados ou em união estável. Há situações prévias de violência, não reconhecidas pelos homens. Há associação com uso de álcool e discussão

LMP ainda em processo de institucionalização e banalização da violência contra a mulher, poucos encaminhamentos e centralidade em ações punitivas aos autores

Melhora no bem-estar e competência parental, principalmente quando abordados aspectos relacionados à violência, juntamente do ensino de manejo positivo com filhos

Mães com histórico familiar de violência. Dificuldade na separação por culpa e pouco apoio. Ambos relataram sentimento de impotência

Alterações na autoestima, sentimento de independência, relações sociais e saúde física e mental. $\mathrm{O}$ atendimento tem influência na ressignificação da violência

Poucos processos são acompanhados pela equipe, que atende na maioria: mulheres que sofreram violência conjugal

contínua, principalmente psicológica e motivada pelo ciúme

Continua 
Continuação

\begin{tabular}{|c|c|c|c|}
\hline $\begin{array}{l}\text { 27. Silveira, \& Nardi } \\
\text { (2014) }\end{array}$ & $\begin{array}{l}\text { Analisar práticas } \\
\text { discursivas jurídicas } \\
\text { sobre gênero, raça e } \\
\text { etnia e seus efeitos }\end{array}$ & $\begin{array}{l}\text { Quantitativo-qualitativo; } \\
\text { pesquisa documental; } \\
\text { entrevistas individuais; } \\
70 \text { processos judiciais e } \\
55 \text { BOs; } 291 \text { mulheres, seis } \\
\text { juízes/juízas }\end{array}$ & $\begin{array}{l}\text { Maioria de mulheres negras } \\
\text { nos boletins de ocorrência, nas } \\
\text { entrevistas, mas não nos processos, } \\
\text { evidenciando diferentes formas de } \\
\text { acesso à justiça }\end{array}$ \\
\hline $\begin{array}{l}\text { 28. Souza, \& Cortez } \\
\text { (2014) }\end{array}$ & $\begin{array}{l}\text { Descrever e analisar } \\
\text { o funcionamento } \\
\text { de uma Delegacia } \\
\text { Especializada de } \\
\text { Atendimento à } \\
\text { Mulher (DEAM) }\end{array}$ & $\begin{array}{c}\text { Estudo de caso qualitativo; } \\
\text { entrevistas; observação; } \\
14 \text { funcionários }\end{array}$ & $\begin{array}{l}\text { Falta de recursos humanos e } \\
\text { materiais, capacitação, valorização } \\
\text { do Estado e apoio da Polícia Civil. } \\
\text { Bom relacionamento entre equipe }\end{array}$ \\
\hline $\begin{array}{l}\text { 29. Zancan, } \\
\text { Wassermann, \& } \\
\text { Lima (2013) }\end{array}$ & $\begin{array}{l}\text { Identificar perfil } \\
\text { de mulheres e suas } \\
\text { percepções sobre } \\
\text { violência }\end{array}$ & $\begin{array}{l}\text { qualitativo; fichas } \\
\text { de dados pessoais e } \\
\text { sociodemográficos; } \\
\text { entrevista semiestruturada; } \\
\text { quatro mulheres que } \\
\text { sofreram violência }\end{array}$ & $\begin{array}{l}\text { Violência psicológica e física } \\
\text { nos quatro casos. Associação } \\
\text { entre ciúme, uso de álcool e } \\
\text { violência. Dificuldade em romper } \\
\text { relacionamento por conta de } \\
\text { ameaças, esperança e valorização } \\
\text { do papel de pai. Violência na família } \\
\text { de origem de ambos os parceiros }\end{array}$ \\
\hline
\end{tabular}

Fonte: Desenvolvida pelas autoras deste artigo.

Dois estudos abordaram as consequências decorrentes da violência (20 e 25), um deles investigando efeitos no casal (20) e outro somente na vida da mulher (25). Cinco estudos detiveram-se a avaliar a rede de enfrentamento à violência $(9,22,26,27$ e 28), analisando as práticas profissionais e os discursos que as permeiam e influenciam o atendimento às mulheres. Quatro deles foram pesquisas documentais (9, 22, 26 e 27). Por fim, quatro estudos avaliaram a efetividade de intervenções realizadas $(4,8,17$ e 23). As/os participantes foram profissionais (4), mulheres que sofreram violência (8 e 23) e homens que a praticaram (17).

Em relação aos principais resultados encontrados, a partir da avaliação de crenças/percepções sobre o fenômeno da violência $(1,3,11,16,18,19$, 24 e 29), foi identificado pelos estudos que, para as mulheres, o ciúme (1, 11 e 29) e o álcool (29) motivaram a violência, sendo o primeiro entendido como uma psicopatologia (11). Em relação à dificuldade em sair do relacionamento violento, houve associação com: valorização da família e dos papéis familiares (1 e 29); existência da mulher voltada ao companheiro (1); sentimentos de ameaça ou de esperança na mudança do comportamento do companheiro (29); e sentimentos de culpa, de impotência e percepção de pouco apoio social para o enfrentamento (24). Ainda, filhas/os participan- tes deste último estudo também apresentaram sentimentos de impotência diante das situações de violência, apesar de se sentirem responsáveis por proteger as mães.

Em relação às crenças de psicólogas da rede, existe o entendimento da violência como uma expressão de desigualdade de gênero construída socialmente. Ademais, o autossacrifício e o ciúme, atrelados à percepção de amor romântico, podem estar vinculados à dificuldade em sair do relacionamento violento (18). Já os discursos de profissionais da rede socioinstitucional indicaram a presença da dualidade vítima-agressor, que reforça relações de poder e enfraquece a autonomia da mulher, e a percepção de violência como um traço de personalidade do homem (3). Em um dos estudos com homens e mulheres foi identificada a presença de violência perpetrada e justificada por ambos, ainda que as partes se considerem também como vítimas (19). Outro estudo, com a prevalência de participantes mulheres, identificou crenças individualizantes sobre estratégias de enfrentamento à violência, sendo estas: revidar com mais violência, fugir do lar, resolver no espaço privado. Ainda, houve a descrença no funcionamento do judiciário (16).

No que se refere à caracterização da violência contra a mulher (2, 6, 14, 15, 21, 26 e 29), a psicológica foi a mais frequente em três estudos (2, 6 e 26) e uma 
das mais praticadas em outro (29). Houve uma diferença entre violências perpetradas principalmente por homens ou mulheres no relacionamento, sendo eles autores de coerção sexual e elas de violência psicológica grave (6). O mesmo estudo aponta maior probabilidade de coerção sexual grave conforme maior o número de filhas/os. Em quatro estudos existe um histórico de situações prévias de violência conjugal $(14,15,21$ e 26). O local de maior ocorrência foi o ambiente doméstico (21).

Em relação ao perfil das mulheres que sofreram violência conjugal nota-se que a maioria é jovem (2 e 6), negra ( 2 e 27) e economicamente menos favorecida (2 e 6). Os fatores de risco ou proteção investigados foram predominantemente individuais: ciúme (7, 14 e 15), separação (14 e 15), ambiguidade de sentimentos e dificuldade em avaliar risco (8), funcionamento patológico da personalidade (12), uso de álcool e discussão doméstica (21). Em âmbito familiar, foi identificada correlação entre violência na família de origem e na relação conjugal, tanto com participantes homens (13), como mulheres e homens (5). Corroborando com este achado, um dos estudos identificou um padrão de repetição de violência intrafamiliar (24). Como fator protetivo, foi assinalado o papel de suporte emocional, aconselhamento e companhia da rede de apoio social das mulheres (10).

Dentre as consequências da violência, mencionada no estudo com enfoque no relacionamento, foi citada a percepção de menor qualidade conjugal. Apesar disso, os casais mantiveram os níveis de satisfação conjugal, demonstrando a naturalização da violência psicológica praticada e sofrida (20). Como consequências individuais em mulheres que sofreram violência foram analisadas alterações nas relações sociais, bem como prejuízos para saúde física e psicológica (25).

As pesquisas que buscaram realizar uma avaliação da rede de enfrentamento encontraram resultados diversos. No que tange a área jurídica, ainda há a banalização da violência contra a mulher pela própria equipe e há poucos encaminhamentos (22). Houve um estudo que identificou diferentes experiências de acesso à justiça para mulheres negras e o desconhecimento de juízes/as sobre a interseccionalidade gênero-raça-etnia (27). Em equipe multidisciplinar também há poucos casos acompanhados, mesmo que sejam de violência contínua, sendo sua principal função subsidiar decisões judiciais (26). Com pro- fissionais de saúde, foi percebida a falta de entendimento da diferença entre notificação e denúncia, a consequente subnotificação, ainda que a partir de 2006 tenha tido crescimento gradativo (9). Em relação a área policial, em uma DEAM houve a percepção de falta de recursos humanos e materiais, falta de articulação entre serviços e de capacitações à equipe (28).

Por fim, as pesquisas que buscaram avaliar a efetividade de intervenções tiveram resultados considerados positivos como: conscientização da realidade violenta em mulheres (8) e homens (17), melhora no bem-estar e competência parental em mulheres/mães (23) e entendimento do papel profissional na identificação, compreensão e manejo de violência (4), apesar de não haver diferença na confiança para atuação.

\section{Discussão}

A violência contra a mulher é um problema de proporção mundial e, devido a sua magnitude, há uma tendência de crescimento nas publicações científicas sobre o assunto. Mais especificamente, a VPI é uma das mais prevalentes e endêmicas formas de violência contra a mulher (Silva, \& Oliveira, 2015), o que ressalta ainda mais a importância de estudos que abordem essa temática. Na presente revisão, percebe-se que existe uma distribuição homogênea ao longo dos anos no número de artigos empíricos encontrados.

Em relação às regiões brasileiras em que os artigos foram produzidos, nota-se que existe uma maior concentração de produção nas regiões Sul e Sudeste do Brasil. É significativo que, apesar das regiões Norte e Nordeste apresentarem um menor número de publicações sobre violência conjugal, são os locais em que há maior prevalência de violência física cometida por parceiro íntimo (Reichenheim et al., 2006). De acordo com o Mapa da Violência (Waiselfisz, 2015), o Centro-Oeste, o Norte e o Nordeste são as regiões com maiores índices de homicídios de mulheres, respectivamente. Além disso, entre 2003 e 2013, houve um crescimento de $79,3 \%$ no Nordeste e de $53,7 \%$ no Norte nas taxas de homicídios e somente a Região Sudeste apresentou decréscimo de 50,3\%. Por outro lado, deve-se considerar que a produção científica nacional é altamente atrelada aos Programas de Pós-Graduação e as regiões Sul e Sudeste concentram a maior parte dos Programas em Psicologia.

Nas últimas décadas, o ativismo de grupos sociais e o desenvolvimento de políticas públicas para o enfrentamento da violência contra a mulher têm 
contribuído para tornar essa forma de violência mais evidente e menos aceitável (Schraiber et al., 2007). No entanto, o crescimento de taxas de homicídios de mulheres na maioria das regiões brasileiras demonstra que isso não implica no término dos atos de violência. Paralelamente a isso, uma pesquisa recente do Ibope (Ibope Inteligência, 2017), que buscou investigar diferentes tipos de preconceito entre os brasileiros, revelou que o discurso machista é mais presente nas regiões Norte e Centro-Oeste do país. Segundo Silva e Oliveira (2015), o direito do homem de subjugar a companheira é, muitas vezes, culturalmente aceito. Concomitantemente, nota-se que, em regiões em que há uma maior incidência do discurso machista e da violência contra a mulher, existe um menor número de produções científicas sobre VPI.

Com relação às/aos participantes, a escassez de estudos com homens autores de agressão indica a necessidade de novas abordagens em se tratando de violência conjugal, que não atribuam um caráter imutável aos homens enquanto agressores e violentos e que não se atenham à lógica culpabilizante-vitimizante. Dessa forma, possibilita-se atingir um maior entendimento acerca da dinâmica da relação conjugal violenta, por meio de discussões sobre os padrões sociais e de gênero (Silva et al., 2015). O envolvimento de homens autores de agressão possibilita, portanto, atingir mudanças mais efetivas no contexto de relações íntimas violentas (Saffioti, 2001), e contribui para a quebra da lógica individualizante de solução atrelada a ações somente direcionadas para mulheres. É importante contribuir para a mudança da lógica punitivista prevalente, adotando uma perspectiva de assistência e suporte também aos homens (Lopes, \& Leite, 2013), como já prevê a Lei Maria da Penha (Lei no 11.340, 2006) no que diz respeito à conscientização e ressocialização de autores de violência. Para o enfrentamento à violência é necessário romper com o modelo de dominação masculina e vitimização feminina, reconhecendo a autonomia da mulher (Santos, \& Izumino, 2005).

Além disso, os dados encontrados mostram a indispensabilidade de estudos com participantes profissionais da rede multidisciplinar de enfrentamento, uma vez que eles são componentes fundamentais para uma intervenção ainda no início do problema e, dessa forma, precisam estar preparados para poder identificar situações de violência (Menezes, Lima, Correia, Souza, Erdmann, \& Gomes, 2014).
A fim de disponibilizar um atendimento integral à mulher, se faz necessária a articulação desses profissionais e dos serviços da rede, a qual envolve as áreas da saúde, assistência social, educação, justiça e segurança pública (Brasil, 2011). Durante o atendimento, é fundamental uma abordagem não culpabilizante, que estimule a autonomia da mulher, dado que esse tipo de violência é uma ramificação da opressão histórica e estrutural às mulheres (Brasil, 2011). Assim, as formas de atendimentos ofertadas influenciam na experiência de enfrentamento e podem prevenir a revitimização (Castro; Silva, 2017).

As abordagens dos estudos analisados variaram entre qualitativas, quantitativas e o uso de ambos, corroborando o entendimento de que a Psicologia é um campo que se mune de diversas práticas metodológicas voltadas para a produção de conhecimento. No que se refere aos métodos e instrumentos utilizados para a coleta de dados, estes mostraram-se coerentes com os objetivos dos estudos. Entretanto, a diversidade de métodos e epistemologias se apresenta na produção científica de forma não integrada e estratificada, ficando evidente também pelos poucos estudos encontrados que combinaram delineamentos diferentes nesta revisão. Este achado também foi constatado em uma pesquisa realizada por Silva, Capra-Ramos, Victorazzi, Lima, Brunnet, \& Pizzinato (2012) sobre a publicação científica em Psicologia no Brasil.

Ressalta-se que os fenômenos de estudo da Psicologia, invariavelmente, compreendem características complexas - como a violência conjugal contra a mulher - e que não conseguirão ser respondidos cientificamente por delineamentos, métodos e análises únicas (Shaughnessy, Zechmeister, \& Zechmeister, 2012). Portanto, os estudos nesta área carecem de abordagens metodológicas que busquem incorporar compreensões complementares sobre o fenômeno, ao invés de ater-se a um entendimento sedimentado e que reforça dicotomias no saber científico. Um limitador importante a respeito das análises se deu porque muitos artigos encontrados nessa revisão sistemática não explicitam seus delineamentos, ficando muitas vezes a cargo das autoras identificá-los.

No que se refere à identificação de crenças de mulheres sobre o fenômeno, o ciúme apareceu como uma das principais causas para as situações de violência conjugal. Comumente, o comportamento ciumento está associado ao direito de posse que o homem acredita deter sobre a mulher, tratando-a 
como sua propriedade. Este entendimento é fruto da desigualdade existente nas relações entre mulheres e homens, na medida em que a construção social de feminilidades e masculinidades ocorre de forma assimétrica (Fonseca, Ribeiro, \& Leal, 2012). O consumo de álcool também é apontado por participantes como fator que predispõe a ocorrência de situações violentas. Embora exista, nos artigos revisados, uma percepção causal entre o fenômeno da violência e o consumo de álcool, entende-se que o álcool apenas potencializa as situações de violência na conjugalidade (Vieira, Cortes, Padoin, Souza, Paula, \& Terra, 2014). Ainda, a permanência de mulheres em relações violentas está associada às expectativas sociais de casamento e constituição da família (Brancaglioni, \& Fonseca, 2016), além do medo de ameaças constantes e a esperança de que o companheiro modifique sua conduta (Zancan, Wassermann, \& Lima, 2013).

No que tange a caracterização da violência, em relação à prevalência da violência psicológica, pode-se pensar em um possível avanço em termos de seu reconhecimento, o qual costuma ser precedido de dificuldades em razão de não deixar marcas no corpo e sim marcas que não são visíveis, caso não seja realizada uma avaliação criteriosa (Costa, Moreira, Henriques, Marques, \& Fernandes, 2011). Esta e as demais violências previstas e criminalizadas pela Lei Maria da Penha devem ser igualmente reconhecidas e denunciadas (Lei no 11.340, 2006). Assim sendo, entende-se a importância de seu reconhecimento, pois a mesma traz prejuízos importantes para saúde mental de mulheres e pode estar atrelada a outras formas de violência (Silva, Coelho, \& Caponi, 2007).

A partir dos resultados, também se corrobora que a violência contra a mulher no relacionamento íntimo, de uma maneira geral, não acontece de forma isolada, apresentando ocorrências prévias. Esses dados evidenciam ainda mais a importância de intervenções que previnam a revitimização (Castro, \& Silva, 2017). Para tanto, há a necessidade de uma equipe profissional especializada e preparada para atender estas situações, para que não mais existam atitudes profissionais que desencorajam a mulher a efetuar a denúncia (22; Garbin, Garbin, Dossi, \& Dossi, 2006; Jong, Sadala, \& Tanaka, 2008).

Apenas um estudo buscou analisar e discutir relações entre raça e gênero. De acordo com o Atlas da Violência (Cerqueira et al., 2017), 65,3\% das mulheres assassinadas no Brasil no último ano eram negras.
Os dados indicam que entre 2005 e 2015 houve um aumento de $22,0 \%$ da mortalidade de mulheres negras, ao passo que a mortalidade de mulheres de outras etnias teve uma redução de $7,4 \%$ no mesmo período. É fundamental reconhecer a invisibilidade de marcadores de raça e etnia na compreensão do fenômeno da violência contra a mulher. Para tanto, as produções científicas podem contribuir avaliando os impactos da violência e do racismo às mulheres, inclusive para fomentar políticas públicas específicas para esta população, visto que ainda carecem de investimento. Ademais, é importante que haja um debate social, não somente em nível acadêmico, sobre a influência midiática para a sexualização e objetificação de mulheres negras no país e sobre a construção sócio-histórica de uma hierarquia de exploração que ainda hoje está enraizada (Romio, 2013).

Com outro resultado significativo, a partir da correlação encontrada entre violência na família de origem e violência conjugal (5 e 13), corrobora-se que estilos parentais são desenvolvidos a partir de experiências na família de origem e têm reverberações na vida adulta (23). Dessa forma, um contexto violento pode oportunizar que a violência seja utilizada como uma estratégia de resolução de problemas, provocando um padrão de comportamento violento (Silva et al., 2007) identificado em um dos estudos (24). Portanto, para atingir o objetivo de romper com este ciclo, são fundamentais intervenções com o casal, como propõe uma das pesquisas de intervenção (23).

Os resultados de pesquisas que se propuseram a avaliar a rede de enfrentamento apontam que ainda são precários os recursos humanos especializados, a infraestrutura e a articulação de serviços que a compõe. Ademais, são realizados poucos encaminhamentos e acompanhamentos, o que pode estar relacionado à subnotificação dos casos, prejudicando a mulher no enfrentamento efetivo à violência. Estes dados vão de encontro ao que propõe a Lei Maria da Penha (Lei no $11.340,2006)$ e a Política Nacional de Enfrentamento à Violência contra as Mulheres (Brasil, 2011).

Por fim, foram escassas as pesquisas com foco na avaliação de intervenções psicológicas. $\mathrm{O}$ estudo que envolve habilidades parentais não discute a necessidade de envolvimento dos homens autores de agressão, ainda que seis das nove participantes permanecessem no relacionamento, de modo que o autor da agressão ainda estaria presente no convívio familiar como companheiro e pai (23). Pode-se identificar uma perspec- 
tiva que implica a mulher como sendo exclusivamente responsável pelo cuidado, reforçando estereótipos de gênero (Giffin, 2005). Em relação às intervenções (8 e 17), a conscientização alcançada por participantes é percebida como fundamental para o rompimento da relação violenta para mulheres e a não reincidência para os homens (Prates, \& Andrade, 2013).

\section{Considerações finais}

A partir desta revisão sistemática de literatura, pode-se identificar a prevalência de estudos que retratam aspectos individuais da VPI, especialmente com mulheres que sofreram violência. Ainda, há carência de estudos que abordem o caráter preventivo do fenômeno, que incluam autores de violência como participantes e que avaliem a efetividade de intervenções. Considerando que a violência se apresenta em diversas etapas do ciclo vital, reafirma-se a importância de estratégias preventivas, principalmente no contexto escolar, espaço promissor para uma discussão pautada na igualdade de gênero que promova a construção de relacionamentos saudáveis. No que tange a metodologia, percebe-se a pouca utilização de méto- dos mistos. Como uma limitação deste estudo, foram incluídos somente artigos publicados em revistas nacionais, portanto não foram contemplados estudos produzidos nacionalmente que tenham sido publicados em revistas internacionais, em razão da menor acessibilidade da população em geral.

Os resultados apresentados podem auxiliar na compreensão do fenômeno da VPI a partir de uma perspectiva mais ampla, a qual engloba aspectos individuais, familiares e socioculturais. Inclusive, estes podem fomentar novas pesquisas, no sentido de apontar potencialidades e carências de estudos empíricos brasileiros de Psicologia sobre a temática. Ademais, é importante o investimento em novas pesquisas que avaliem intervenções tanto preventivas como terapêuticas, tendo em vista a influência da violência na família de origem na vivência de VPI e as graves consequências individuais, familiares e sociais. A Psicologia enquanto ciência e profissão assume um papel importante na rede de serviços de atendimento e a produção científica na área é um dispositivo de formulação de políticas públicas que contribui no enfrentamento do fenômeno da violência contra a mulher.

\section{Referências}

Angelim, F. P., \& Diniz, G. R. S. (2009). O pessoal torna-se político: o papel do Estado no monitoramento da violência contra as mulheres. Revista Psicologia Política, 9(18), 259-274. Recuperado de http://pepsic.bvsalud.org/pdf/ rpp/v9n18/v9n18a06.pdf

Azevedo, A. K. S., \& Dutra, E. M. S. (2015). Não há você sem mim: histórias de mulheres sobreviventes de uma tentativa de homicídio. Revista Subjetividades, 15(2), 201-213. Recuperado de http://pepsic.bvsalud.org/scielo. php?script=sci_arttext\&pid=S2359-07692015000200004\&lng=pt\&tlng=pt.

Bandeira, L. M., \& Almeida, T. M. C. (2015). Vinte anos da Convenção de Belém do Pará e a Lei Maria da Penha. Revista Estudos Feministas, 23(2), 501-517. https://doi.org/10.1590/0104-026X2015v23n2p501

Barros, E. N., Silva, M. A., Falbo Neto, G. H., Lucena, S. G., Ponzo, L., \& Pimentel, A. P. (2015). Prevalência e fatores associados à violência por parceiro íntimo em mulheres de uma comunidade em Recife/Pernambuco, Brasil. Ciência \& Saúde Coletiva, 21(2), 591-598. https://doi.org/10.1590/1413-81232015212.10672015

Bicalho, P. G., Magalhães, K. C., Cassal, L. C. B., \& Geraldini, J. R. (2012). Cinquenta anos de produção do conhecimento: práticas políticas da pesquisa em Psicologia. Psicologia: Ciência e Profissão, 32(n.spe), 264-275. https://doi.org/10.1590/S1414-98932012000500019

Brancaglioni, B. C. A., \& Fonseca, R. M. G. S. (2016). Violência por parceiro íntimo na adolescência: uma análise de gênero e geração. Revista Brasileira de Enfermagem, 69(5), 946-955. https:// doi.org/10.1590/0034-7167-2016-0408

Braun, V., \& Clarke, V. (2006). Using thematic analysis in psychology. Qualitative Research in Psychology, 3(2), 77-101. Recuperado de: http://eprints.uwe.ac.uk/11735/2/thematic_analysis_revised_-_final.pdf

Brasil (2011). Política Nacional de Enfrentamento à Violência contra as Mulheres. Brasília, DF: Secretaria Nacional de Enfrentamento à Violência contra as Mulheres, 2011. Recuperado de https://www12.senado. leg.br/institucional/omv/entenda-a-violencia/pdfs/politica-nacional-de-enfrentamento-a-violencia-contra-as-mulheres 
Brasil (2016). Ministério da Justiça e Cidadania. Secretaria Especial de Políticas para as Mulheres. Ligue 180 Central de Atendimento à Mulher. balanço $1^{\circ}$ semestre 2016. Brasília, DF, Centro Cultural Banco do Brasil. Recuperado de http://www.mulheres.ba.gov.br/arquivos/File/Publicacoes/Balanco_Ligue180_1semestre2016.pdf

Bruhn, M. M., \& Lara, L. (2016). Rota crítica: a trajetória de uma mulher para romper o ciclo da violência doméstica. Revista Polis e Psique, 6(2), 70-86. Recuperado de http://pepsic.bvsalud.org/scielo.php?script=sci_arttex$\mathrm{t} \& \mathrm{pid}=\mathrm{S} 2238-152 X 2016000200005 \& \operatorname{lng}=\mathrm{pt} \& \operatorname{lng}=\mathrm{pt}$

Brum, C. R. S., Lourenço, L. M., Gebara, C. F. P., \& Ronzani, T. M. (2013). Violência doméstica e crenças: intervenção com profissionais da atenção primária à saúde. Psicologia em Pesquisa, 7(2), 242-250. Recuperado de https://doi.org/10.5327/Z1982-1247201300020012

Castro, B. D. V., \& Silva, A. S. (2017). Atuação da autoridade policial e do poder judiciário no combate à violência doméstica contra a mulher na cidade de São Luís/MA. Opinião Jurídica, 15(20), 59-83. https:// doi.org/10.12662/2447-6641oj.v15i20.p59-83.2017

Cerqueira, D., Lima, R. S., Bueno, S., Valencia, L. I., Hanashiro, O., Machado, P. H. G., et al.. (2017). Atlas da violência. Rio de Janeiro: IPEA.

Colossi, P. M., Marasca, A. R., \& Falcke, D. (2015). De geração em geração: a violência conjugal e as experiências na família de origem. Psico, 46(4), 493-502. https://doi.org/10.15448/1980-8623.2015.4.20979

Colossi, P. M., Razera J., Haack K. R., \& Falcke, D. (2015). Violência conjugal: prevalência e fatores associados. Contextos Clínicos, 8(1), 55-66. https://doi.org/10.4013/ctc.2015.81.06

Conselho Federal de Psicologia - CFP, \& Conselhos Regionais de Psicologia (2013). Referências técnicas para atuação de psicólogas (os) em Programas de Atenção à Mulher em situação de violência. Brasília, DF. http:/ /crepop.pol. org.br/wp-content/uploads/2013/05/2013-05-02b-MULHER.pdf

Costa, A. B., \& Zoltowski, A. P. C. (2014). Como escrever um artigo de revisão sistemática. In: S. H. Koller, M. C. P. Couto, \& J. V. Hohendorff, Manual de produção científica (pp.50-84). Porto Alegre: Penso.

Costa, A. M., Moreira, K. A. P., Henriques, A. C. P. T., Marques, J.F., \& Fernandes, A. F. C. (2011). Violência contra a mulher: caracterização de casos atendidos em um Centro estadual de referência. Revista Rene, 12(3), 627-635. Recuperado de https://www.semanticscholar.org/paper/Viol\%C3\%AAncia-contra-a-mulher\%3A-caracteriza\%C3\%A7\%C3\%A3o-de-casos-Costa-Moreira/b64a4e2facd64f16d9f00208630cf59b8f028affX

Costa, N., Gomes, H., Almeida, T., Pinheiro, R. S., Almeida, C., Gondim, L., et al. (2016). Violence against women: Can "jealousy" mitigate the significance of violence? Estudos de Psicologia (Campinas), 33(3), 525-533. https://doi.org/10.1590/1982-02752016000300015

Fonseca, D. H., Ribeiro, C. G. \& Leal, N. S. B. (2012). Violência doméstica contra a mulher: realidades e representações sociais. Psicologia \& Sociedade, 24(2), 307-314. https://doi.org/10.1590/S0102-71822012000200008

Garbin, C. A. S., Garbin, A. J. I., Dossi, A. P., \& Dossi, M. O. (2006). Violência doméstica: análise das lesões em mulheres. Cadernos de Saúde Pública, 22(12), 2567-2573. https://doi.org/10.1590/S0102-311X2006001200007

Giffin, K. (2005). A inserção dos homens nos estudos de gênero: contribuições de um sujeito histórico. Ciência \& Saúde Coletiva, 10(1), 47-57. https://doi.org/10.1590/S1413-81232005000100011

Guimarães, F. L., Diniz, G. R. S. \& Angelim, F. P. (2017). “Mas ele diz que me ama...”: Duplo-vínculo e nomeação da violência conjugal. Psicologia: Teoria e Pesquisa, 33: e3346. https://dx.doi.org/10.1590/0102.3772e3346

Ibope Inteligência (2017). 7 entre cada 10 brasileiros já fizeram comentários preconceituosos. Recuperado de http://www.ibopeinteligencia.com/noticias-e-pesquisas/7-entre-cada-10-brasileiros-ja-fizeram-comentarios-preconceituosos/

Jong, L. C., Sadala, M. L. A., \& Tanaka, A. C. D. (2008). Desistindo da denúncia do agressor: Relato de mulheres vítimas de violência doméstica. Revista da Escola de Enfermagem da USP, 42(4), 744-51. https://doi.org/10.1590/S0080-62342008000400018

Kind, L., Orsini, M. L. P., Nepomuceno, V., Gonçalves, L., Souza, G. A., \& Ferreira, M. F. F. (2013). Subnotificação e (in) visibilidade da violência contra mulheres na atenção primária à saúde. Cadernos de Saúde Pública, 29(9), 18051815. https:// doi.org/10.1590/0102-311X00096312

Krenkel, S., Moré, C. L. O. O., \& Motta, C. C. L. (2015). The significant social networks of women who have resided in shelters. Paidéia (Ribeirão Preto), 25(60), 125-133. https://doi.org/10.1590/1982-43272560201515 
Krug, E. G., Dahlberg, L. L., Mercy, J. A., Zwi, A. B., \& Lozano, R. (Eds.). (2002). Relatório mundial sobre violência e saúde. Genebra: Organização Mundial da Saúde.

Lacerda, L., \& Costa, N. (2013). Relação entre comportamentos emocionais ciumentos e violência contra a mulher. Revista Brasileira de Terapia Comportamental e Cognitiva, 15(3), 21-36. Recuperado de http://pepsic. bvsalud.org/scielo.php?script=sci_arttext\&pid=S1517-55452013000300003\&lng=pt\&tlng=pt

Lei no 11.340, de 7 de agosto de 2006. Cria mecanismos para coibir a violência doméstica e familiar contra a mulher, nos termos do $\S 8^{\circ}$ do art. 226 da Constituição Federal, da Convenção sobre a Eliminação de Todas as Formas de Discriminação contra as Mulheres e da Convenção Interamericana para Prevenir, Punir e Erradicar a Violência contra a Mulher; dispõe sobre a criação dos Juizados de Violência Doméstica e Familiar contra a Mulher; altera o Código de Processo Penal, o Código Penal e a Lei de Execução Penal; e dá outras providências. Diário Oficial da União, 8 ago. 2006

Lei no 13.104, de 9 de março de 2015. Altera o art. 121 do Decreto-Lei no 2.848, de 7 de dezembro de 1940 Código Penal, para prever o feminicídio como circunstância qualificadora do crime de homicídio, e o art. $1^{\circ}$ da Lei $\mathrm{n}^{\circ}$ 8.072, de 25 de julho de 1990, para incluir o feminicídio no rol dos crimes hediondoss. Diário Oficial da União, 10 mar. 2015.

Leonardi, J. L., \& Meyer, S. B. (2015). Prática baseada em evidências em psicologia e a história da busca pelas provas empíricas da eficácia das psicoterapias. Psicologia: Ciência e Profissão, 35(4), 1139-1156. https://doi.org/10.1590/1982-3703001552014

Lopes, P. V. L., \& Leite, F. (orgs.). (2013). Atendimento a homens autores de violência doméstica: desafios à política pública. Rio de Janeiro: Instituto de Estudos da Religião. Recuperado de http:/ /www.iser.org.br/site/wp-content/ uploads/2013/11/homens_miolo_9nov_.pdf

Madalena, M. B. A., Falcke, D., \& Carvalho, L. F. (2015). Violência conjugal e funcionamentos patológicos da personalidade. Arquivos Brasileiros de Psicologia, 67(2), 122-139. Recuperado de http://pepsic.bvsalud.org/scielo. php?script=sci_arttext\&pid=S1809-52672015000200010\&lng=pt\&tlng=pt

Marasca, A. R., Razera, J., Pereira, H. J. R., \& Falcke, D. (2017). Marital physical violence suffered and committed by men: repeating family patterns?. Psico-USF, 22(1), 99-108. https://doi.org/10.1590/1413-82712017220109

Martins-Borges, L., Girardi, J. F., \& Lodetti, M. B. (2017). Homicídios conjugais na grande Florianópolis: Notícias publicadas no diário catarinense. Pesquisas e Práticas Psicossociais, 12(1), 9-22. Recuperado de http://pepsic. bvsalud.org/scielo.php?script=sci_arttext\&pid=S1809-89082017000100002\&lng=pt\&tlng=pt.

Martins-Borges, L., Lodetti, M. B., Tridapalli, A. L., \& Machado, G. S. (2016). Homicídio conjugal na grande São Paulo e na grande Florianópolis: notícias publicadas em jornais. Gerais: Revista Institucional de Psicologia, 9(2), 227-240. Recuperado de http:// pepsic.bvsalud.org/scielo.php?script=sci_arttext\&pid=S1983-82202016000200006\&lng=pt

Mendonça, M. F. S., \& Ludermir, A. B. (2017). Violência por parceiro íntimo e incidência de transtorno mental comum. Revista de Saúde Pública, 51:32. https://doi.org/10.1590/s1518-8787.2017051006912

Menezes, P. R. M., Lima, I. S., Correia, C. M. C., Souza, S. S., Erdmann, A. L., \& Gomes, N. P. (2014). Enfrentamento da violência contra a mulher: articulação intersetorial e atenção integral. Saúde e Sociedade, 23(3), 778-786. https://doi.org/10.1590/S0104-12902014000300004

Mühlen, B. K., \& Strey, M. N. (2013). Avanços e retrocessos no combate da violência contra mulheres. Athenea Digital, 13(2), 229-237. Recuperado de https://ddd.uab.cat/pub/athdig/athdig_a2013m7v13n2/athdig_ a2013m7v13n2p229.pdf

Oliveira, E. C. S., \& Araújo, M. F. (2014). O Teatro Fórum como dispositivo de discussão da violência contra a mulher. Estudos de Psicologia (Campinas), 31(2), 257-267. https://doi.org/10.1590/0103-166X2014000200011

Paixão, G. P. N., Gomes, N. P., Diniz, N. M. F., Couto, T. M., Vianna, L. A. C., \& Santos, S. M. P. (2014). Situações que precipitam conflitos na relação conjugal: O discurso de mulheres. Texto \& Contexto Enfermagem, 23(4), 10411049. https:// doi.org/10.1590/0104-07072014003290013

Pimentel, A. (2016). Grupos existenciais para conscientização de homens. Revista do NUFEN, 8(1), 55-75. Recuperado de http://pepsic.bvsalud.org/scielo.php?script=sci_arttext\&pid=S2175-25912016000100005\&lng= pt\&tlng=pt

Porto, M., \&Buchrer-Maluschke,J.S.N.F. (2014).Apermanência demulheres emsituações deviolência:considerações de psicólogas. Psicologia: Teoria e Pesquisa, 30(3), 267-276. https://doi.org/10.1590/S0102-37722014000300004 
Prates, P. L., \& Andrade, L. F. (2013, setembro). Grupos reflexivos como medida judicial para homens autores de violência contra a mulher: O contexto sócio-histórico. Seminário Internacional Fazendo Gênero, Florianópolis, SC, Brasil, 10. Recuperado de https://www.fg2013.wwc2017.eventos.dype.com.br/resources/anais/20/1373299497_ ARQUIVO_PrateseAndradeFazendoGenero10.pdf

Ramos, M. E. C. (2013). Homens e mulheres envolvidos em violência e atendidos em grupos socioterapêuticos: União, comunicação e relação. Revista Brasileira de Psicodrama, 21(1), 39-53. Recuperado de http://pepsic.bvsalud.org/scielo.php?script=sci_arttext\&pid=S0104-53932013000100004\&lng=pt\&tlng=pt

Razera, J., Mosmann, C. P., \& Falcke, D. (2016). The interface between quality and violence in marital relationships. Paidéia (Ribeirão Preto), 26(63), 71-79. https://doi.org/10.1590/1982-43272663201609

Reichenheim, M. E., Moraes, C. L., Szklo, A., Hasselmann, M. H., Souza, E. R., Lozana, J. A., et al. (2006). The magnitude of intimate partner violence in Brazil: portraits from 15 capital cities and the Federal District. Cadernos de Saúde Pública, 22(2), 425-437. https://doi.org/10.1590/S0102-311X2006000200020

Romagnoli, R. C. (2015). Várias Marias: Efeitos da Lei Maria da Penha nas delegacias. Fractal: Revista de Psicologia, 27(2), 114-122. https://doi.org/10.1590/1984-0292/1038

Romagnoli, R. C., Abreu, L. L. G., \& Silveira, M. F. (2013). A violência contra a mulher em Montes Claros: análise estatística. Gerais: Revista Interinstitucional de Psicologia, 6(2), 282-297. Recuperado de http://pepsic.bvsalud. org/scielo.php?script=sci_arttext\&pid=S1983-82202013000200010\&lng=pt\&tlng=pt

Romio, J. A. F. (2013). A vitimização de mulheres por agressão física segundo raça e cor no Brasil. In M. M. Marcondes, L. Pinheiro, C. Queiroz, A. C. Querino, \& D. Valverde (Orgs.), Dossiê mulheres negras: Retrato das condições de vida das mulheres negras no Brasil (pp. 133-158). Brasília, DF: Ipea.

Rosa, D. O. A., Ramos, R. C. Z., Melo, E. M., \& Melo, V. H. (2013). A violência contra a mulher provocada por parceiro íntimo. Femina, 41(2), 81-87. Recuperado de http://files.bvs.br/upload/S/0100-7254/2013/v41n2/a3793.pdf

Ribeiro, M. (2010, junho). Movimento feminista na fonte dos centros de combate à violência contra mulheres. Anais do Simpósio sobre Estudos de Gênero e Políticas Públicas, Londrina, PR, Brasil, 1. Recuperado de http://www. uel.br/eventos/gpp/pages/arquivos/5.MonicaDias.pdf

Saffioti, H. I. B. (2001). Contribuições feministas para o estudo da violência de gênero. Cadernos Pagu (16), 115-136. https:// doi.org/10.1590/S0104-83332001000100007

Saffioti, H. I. B. (1997). Violência doméstica ou a lógica do galinheiro. In: M. Kupstas, Violência em debate (p.39-57). São Paulo: Moderna.

Saffioti, H. I. B., \& Almeida, S. S. (1995). Violência de gênero: poder e impotência. Rio de Janeiro: Livraria e Editora Revinter

Santini, P. M., \& Williams, L. C. A. (2016). Efeitos de procedimentos para maximizar o bem-estar e a competência parental em mulheres vitimizadas. Estudos de Psicologia (Campinas), 33(4), 711-721. https://doi.org/10.1590/1982-02752016000400014

Santos, C. M., \& Izumino, W. P. (2005). Violência contra as mulheres e violência de gênero: Notas sobre estudos feministas no Brasil. Estudios Interdisciplinares de America Latina y El Caribe, 16(1), 147-164. Recuperado de http://eial.tau.ac.il/index.php/eial/article/viewFile/482/446

Santos, A. R., Marin, A. H., \& Castoldi, L. (2013). Percepção de mães e adolescentes sobre a violência intrafamiliar por meio da construção do genograma. Contextos Clínicos, 6(2), 174-184. https://doi.org/10.4013/ctc.2013.62.10

Schraiber, L. B., D’Oliveira, A. F. P. L., França-Junior, I., Diniz, S., Portella, A. P., Ludermir, A. B. et al. (2007). Prevalência da violência contra a mulher por parceiro íntimo em regiões do Brasil. Revista de Saúde Pública, 41(5), 797-807. https:// doi.org/10.1590/S0034-89102007000500014

Scott, J.W. (1995). Gênero: uma categoria útil de análise histórica. Educação \& Realidade, 20(2), 71-99. Recuperado de https://seer.ufrgs.br/index.php/educacaoerealidade/article/view/71721

Shaughnessy, J. J., Zechmeister, E. B., \& Zechmeister, J. S. (2012). Metodologia de Pesquisa em Psicologia (9a ed.). Porto Alegre, RS: AMGH.

Silva, C. F. L., \& Tilio, R. (2014). Alterações autobiográficas em mulheres vitimadas atendidas pela rede de acolhimento. Revista Subjetividades, 14(3), 475-485. Recuperado de http://pepsic.bvsalud.org/scielo.php?script=sci arttext\&pid=S2359-07692014000300011\&lng=pt\&tlng=pt 
Silva, L. E. L., \& Oliveira M. L. C. (2015). Violência contra a mulher: revisão sistemática da produção científica nacional no período de 2009 a 2013. Ciência e Saúde Coletiva, 20(11), 3523-3532. https://doi.org/10.1590/1413-812320152011.11302014

Silva, L. L., Coelho, E. B. S., \& Caponi, S. N. C. (2007). Violência silenciosa: violência psicológica como condição da violência física doméstica. Comunicação, Saúde, Educação, 11(21), $93-103$. https://doi.org/10.1590/S1414-32832007000100009

Silva, O. M. A., Alípio, M. P. P., \& Moreira, L. E. (2016). Mulheres e violência doméstica: relato de experiência num juizado especializado. Revista Polis e Psique, 6(3), 145-165. Recuperado de http://pepsic.bvsalud.org/scielo.php?script=sci_arttext\&pid=S2238-152X2016000300009\&lng=pt\&tlng=pt

Silva, T. L. G., Capra-Ramos, C., Victorazzi, A. R., Lima, C. W. M., Brunnet, A. E., \& Pizzinato, A. (2012). Análise temática e metodológica da publicação científica em Psicologia no Brasil. Psicologia em Revistas, 18(2), 330-346. Recuperado de http://pepsic.bvsalud.org/pdf/per/v18n2/v18n2a11.pdf

Silveira, R. S. \& Nardi, H. C. (2014). Interseccionalidade gênero, raça e etnia e a lei Maria da Penha. Psicologia \& Sociedade; 26(n. spe.), 14-24. Recuperado de http://www.scielo.br/pdf/psoc/v26nspe/03.pdf

Silveira, R. S., Nardi, H. C. \& Spindler, G. (2014). Articulações entre gênero e raça/cor em situações de violência de gênero. Psicologia \& Sociedade, 26(2), 323-334. https://doi.org/10.1590/S0102-71822014000500003

Souza, L., \& Cortez, M. B. (2014). A delegacia da mulher perante as normas e leis para o enfrentamento da violência contra a mulher: um estudo de caso. Revista de Administração Pública, 48(3), 621-639. https://dx.doi. org/10.1590/0034-76121141

Vieira, L. B., Cortes, L. F., Padoin, S. M. M., Souza, I. E. O., Paula, C. C., \& Terra, M. G. (2014). Abuso de álcool e drogas e violência contra as mulheres: denúncias de vividos. Revista Brasileira de Enfermagem, 67(3), 366-372. https://doi.org/10.5935/0034-7167.20140048

Waiselfisz, J. J. (2015). Mapa da Violência: Homicídio de mulheres no Brasil. Recuperado de http://www.mapadaviolencia.org.br/

Zancan, N., Wassermann, V., \& Lima, G. Q. (2013). A violência doméstica a partir do discurso de mulheres agredidas. Pensando Famílias, 17(1), 63-76. Recuperado de http://pepsic.bvsalud.org/scielo.php?script=sci_arttext\&pid=S1679494X2013000100007\&lng=pt\&tlng=pt

\section{Beatriz Gross Curia}

Mestre em Psicologia pela Pontifícia Universidade Católica do Rio Grande do Sul, Porto Alegre - RS. Brasil.

E-mail: beatriz.curia@gmail.com

(iD https://orcid.org/0000-0003-2249-7815

\section{Victória Dias Gonçalves}

Psicóloga pela Pontifícia Universidade Católica do Rio Grande do Sul, Porto Alegre - RS. Brasil.

E-mail: victoriadiasgoncalves@gmail.com

(iD https://orcid.org/0000-0002-7630-054X

\section{Júlia Carvalho Zamora}

Doutoranda em Psicologia pela Pontifícia Universidade Católica do Rio Grande do Sul, Porto Alegre - RS. Brasil.

E-mail: juliaczamora@hotmail.com

(iD https://orcid.org/0000-0002-9256-1336

\section{Aline Ruoso}

Graduanda em Psicologia pela Pontifícia Universidade Católica do Rio Grande do Sul, Porto Alegre - RS. Brasil.

E-mail: ruoso.aline@gmail.com

iD https://orcid.org/0000-0003-1177-8777 


\section{Isadora Silveira Ligório}

Mestranda em Psicologia pela Pontifícia Universidade Católica do Rio Grande do Sul, Porto Alegre - RS. Brasil.

E-mail: isa.ligorio@gmail.com

(iD https:// orcid.org/0000-0002-5503-238X

\section{Luísa Habigzang}

Doutora em Psicologia pela Universidade Federal do Rio Grande do Sul e professora do Programa de Pós-Graduação pela Pontifícia Universidade Católica do Rio Grande do Sul, Porto Alegre - RS. Brasil.

E-mail: luisa.habigzang@pucrs.br

(iD) https://orcid.org/0000-0002-0262-0356

Endereço para envio de correspondência:

Pontifícia Universidade Católica do Rio Grande do Sul. Av. Ipiranga, 6681 - Prédio 11, $9^{\circ}$ andar, sala 924.

CEP: 90619-900. Porto Alegre - RS. Brasil.

Recebido 15/12/2017

Aceito 01/03/2019

Received $12 / 15 / 2017$

Approved 03/01/2019

Recibido 15/12/2017

Aceptado 01/03/2019

Como citar: Curia, B. G.; Dias, V.; Zamora, J. C.; Ruoso, A.; Ligório, I. S. \& Habigzang, L (2020). Produções científicas brasileiras em Psicologia sobre violência contra mulher por parceiro íntimo. Psicologia: Ciência e Profissão, 40, 1-19. https://doi.org/10.1590/1982-3703003189184

How to cite: Curia, B. G.; Dias, V.; Zamora, J. C.; Ruoso, A.; Ligório, I. S. \& Habigzang, L (2020). Brazilian scientific productions in Psychology on violence against women by intimate partner. Psicologia: Ciência e Profissão, 40, 1-19. https://doi.org/10.1590/1982-3703003189184

Cómo citar: Curia, B. G.; Dias, V.; Zamora, J. C.; Ruoso, A.; Ligório, I. S. \& Habigzang, L (2020). Producciones científicas brasileñas en Psicología sobre la violencia contra la mujer por pareja íntima. Psicologia: Ciência e Profissão, 40, 1-19. https://doi.org/10.1590/1982-3703003189184 
Na Revista Psicologia: Ciência e Profissão, 40, https://doi.org/10.1590/1982-3703003189184, no artigo "Produções Científicas Brasileiras em Psicologia sobre Violência contra Mulher por Parceiro Íntimo”, na página 1, abaixo do nome da autora Luísa Habigzang, onde se lê: "Universidade Federal do Rio Grande do Sul, RS, Brasil.”, o correto é: “Pontifícia Universidade Católica do Rio Grande do Sul, RS, Brasil." 